\title{
Group demography affects ant colony performance and individual speed of queen and worker aging
}

\author{
Julia Giehr*, Jürgen Heinze and Alexandra Schrempf
}

\begin{abstract}
Background: The performance and fitness of social societies mainly depends on the efficiency of interactions between reproductive individuals and helpers. Helpers need to react to the group's requirements and to adjust their tasks accordingly, while the reproductive individual has to adjust its reproductive rate. Social insects provide a good system to study the interrelations between individual and group characteristics. In general, sterile workers focus on brood care and foraging while the queen lays eggs. Reproductive division of labor is determined by caste and not interchangeable as, e.g., in social mammals or birds. Hence, changing social and environmental conditions require a flexible response by each caste. In the ant Cardiocondyla obscurior, worker task allocation is based on age polyethism, with young workers focusing on brood care and old workers on foraging. Here, we examine how group age demography affects colony performance and fitness in colonies consisting of only old or young workers and a single old or young queen. We hypothesized that both groups will be fully functional, but that the forced task shift affects the individuals' performance. Moreover, we expected reduced worker longevity in groups with only young workers due to precocious foraging but no effect on queen longevity depending on group composition.

Results: Neither the performance of queens nor that of workers declined strongly with time per se, but offspring number and weight were influenced by queen age and the interaction between queen and worker age. Individual residual life expectancy strongly depended on colony demography instead of physiological age. While worker age affected queen longevity only slightly, exposing old workers to the conditions of colony founding increased their life spans by up to $50 \%$ relative to workers that had emerged shortly before colony set-up.

Conclusions: The social environment strongly affected the tempo of aging and senescence in C. obscurior, highlighting the plasticity of life expectancy in social insects. Furthermore, colonies obtained the highest reproductive output when consisting of same-aged queens and workers independent of their physiological age. However, workers appeared to be able to adjust their behavior to the colony's needs and not to suffer from agedependent restrictions.
\end{abstract}

Keywords: Group demography, Social insects, Aging, Task performance, Colony productivity

\section{Background}

The performance of animal societies relies critically on the traits of individual group members, and the quality of their interactions (e.g. [1-3]). At the same time, social environment and task allocation may strongly affect traits of the individual, including learning capability, susceptibility to diseases, and "personality" [4-7].

\footnotetext{
* Correspondence: julia.giehr@biologie.uni-regensburg.de Zoology/ Evolutionary Biology, University of Regensburg, D-93053

* Correspondence: julia
Zoology/ Evolutionary
Regensburg, Germany
}

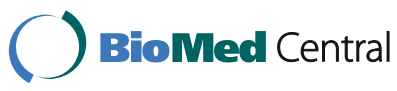

(c) The Author(s). 2017 Open Access This article is distributed under the terms of the Creative Commons Attribution 4.0 International License (http://creativecommons.org/licenses/by/4.0/), which permits unrestricted use, distribution, and reproduction in any medium, provided you give appropriate credit to the original author(s) and the source, provide a link to the Creative Commons license, and indicate if changes were made. The Creative Commons Public Domain Dedication waiver (http://creativecommons.org/publicdomain/zero/1.0/) applies to the data made available in this article, unless otherwise stated.
Social insects represent a suitable system to study how differences between individual group members and the composition of the group affect the fitness of the group $[8,9]$. Insect societies are characterized by reproductive division of labor between queens (in termites also kings) and sterile helpers (workers). In addition, workers of many species specialize on different non-reproductive tasks. While task allocation among workers may be influenced by their experience, morphology, genetic background, and social interactions [10-13], in many species the chronological age of workers plays a major role: 
younger individuals preferentially engage in brood care in the nest, while older individuals focus on foraging outside and nest defense [14-18].

Nevertheless, the behavioral trajectory is far from unidirectional and can be reversed in response to environmental or social challenges [17, 19-21]. For example, the removal of older nestmates induces young workers to forage precociously and foragers may return to brood care activities if needed. Precocious foraging and reversal to nursing may be associated with an expansion of the behavioral repertoire of individuals [18]. However, studies on honeybees and a few ant species indicate that task reversal may result in weaker individual performance [22-25] and can also affect the individual longevity of workers [26, 27].

Similar to workers, the behavior and productivity of queens may change with age. For example, while young queens of Temnothorax rugatulus are capable of solitary founding and independently rearing their first offspring, older queens lose this capability [28]. In Cardiocondyla obscurior, the egg laying rate of queens increases with age until shortly before their death and old queens of several ant species [29-31] produce more female sexual offspring than young queens even when provided with the same number of workers. Any disruption of the natural age structure of insect colonies might therefore influence their performance [32], but the effects of behavioral flexibility on the robustness of division of labor and colony fitness remain largely unstudied [20].

Here we take an extreme approach to examine the consequences of age demography on colony productivity and individual life expectancies of queens and workers in the ant Cardiocondyla obscurior. In this ant, division of labor among workers in natural colonies follows a typical age polyethism ([33]; AS, unpublished results). In a full-factorial design we set up experimental colonies with either freshly eclosed or 12 week old queens, and either freshly eclosed or 12 week old workers. This forced workers to forage prematurely or to reverse to nursing to sustain the colony and exposed queens of a given age to a novel social environment. We investigated whether manipulated workers were less efficient due to presumed behavioral or physiological constrains (see [20-25]) or whether worker task performance is rather independent of age [34]. Our results show that both colonies with only young or only old workers were able to raise offspring. Yet, colony performance was strongly affected by its age composition. Furthermore, the residual lifespan of queens and workers depended more on group composition than on chronological age. Hence, we can show that colony age demography affects worker task allocation and physiology in ants, as previously shown in honey bees [26, 35-37].

\section{Methods}

(a) study species and experimental set-up

C. obscurior is a small (body length approximately $1.5 \mathrm{~mm}$ ) myrmicine ant, which human activities have accidentally introduced from its presumed origin in Southeast Asia throughout the tropics and subtropics [38]. Its colonies consist of one or several queens and a few dozen workers [39] and nest in preformed cavities in trees, such as galls, rolled lemon leaves, or aborted coconuts [40, 41]. Female sexuals and wingless males are produced year-round and readily mate in the natal nest, resulting in high inbreeding levels [38, 32]. Queens lay one or two eggs per day and live on average for 26 weeks [42]. Workers are completely sterile and have a life expectancy of 12 to 16 weeks [43].

Our study colonies were derived from six split colonies originating from one large laboratory stock colony originally collected in a population introduced to Ilhéus, Brazil. Colonies in Brazil are genetically depauperate and highly inbred [44]. Hence, possible effects due to different genetic "lineages" are reduced and observed differences between crosses are most likely due to physiological processes. Colonies were housed in $9.6 \times 9.6 \times 3 \mathrm{~cm}^{3}$ plastic boxes with a plaster floor and three chambers for the nest cavity, food, and water. They were kept in incubators at nearnatural day/night cycles of $12 \mathrm{~h} 25^{\circ} \mathrm{C} / 12 \mathrm{~h} 24{ }^{\circ} \mathrm{C}$ and fed three times per week with cockroaches or fruit flies and honey. The number of individuals, brood items, and dead ants was counted twice per week during the complete experiment.

The experiment consisted of two phases. The purpose of the first phase was to create colonies with "old" workers and queens. In the second phase, these old individuals were used to create experimental colonies with old workers and young queens from the stock colonies and vice versa.

Phase I: 32 experimental colonies were set up within one week with 30 worker pupae, one queen pupa, and one male pupa from split colonies derived from one original stock colony from Bahia, Brazil. To be able to replace dead workers with individuals of similar age at the beginning of phase II, for each stock colony we set up "back-up colonies" with at least 30 worker pupae and several queen pupae depending on availability. Dead pupae or adults were replaced during the first week to maintain the standardized group composition of 30 workers, one queen and one male. All pupae hatched within the first week (week 0); hence the age of nestmates did not differ for more than seven days. Subsequently, colonies were scanned twice a week, egg number was counted, and all newly produced pupae were removed (after caste and number had been recorded) to avoid that young individuals eclosed during this period. Three 
experimental colonies failed to establish a reproducing colony (two queens died within one week after the first egg was laid, one colony strongly decreased in size until all workers had been dead). These colonies were excluded from further experiments. After twelve weeks, $39 \%$ of the workers from the remaining 29 colonies had died and queens were in the middle of their average reproductive lifespan [42]. Twelve-week old workers and queens are referred to as "old."

Phase II: Twelve weeks after the original colonies had been set up we removed all brood items from the successfully established colonies $(n=29$, mean \pm sd: $7.18 \pm 3.2$ eggs and $17.5 \pm 4.4$ larvae, Fig. 1 ) and added workers from the "back-up colonies" to standardize the initial number of workers per colony to 20 . The "old" workers and queens, and pupae from the stock colonies were randomly assigned to create colonies with an old queen and 20 young workers (OQYW, $n=8$ ), young queens and 20 old workers (YQOW, $n=11$ ), and, by reciprocal exchanges, with old queens and old workers (OQOW, $n=10$ ). In addition, new colonies were created with young queens and young workers for comparisons (YQYQ, $n=10$ ). We recorded the age of death of queens and counted the number of eggs, larvae, and pupae in the colonies twice per week without removing brood items until all individuals in a colony had died. Ants initially react sensitively to experimental manipulations, which can result in the accidental death of some individuals shortly after colony set-up (e.g., by drowning in honey before the colony was successfully established). Furthermore, several queens disappeared or did not lay any eggs. Hence only 19 of these 29 colonies could be considered for the analysis of lifespans and brood production (OQOW $n=5$; OQYW $n=6$, YQOW $n=3$; YQYW $n=5)$.

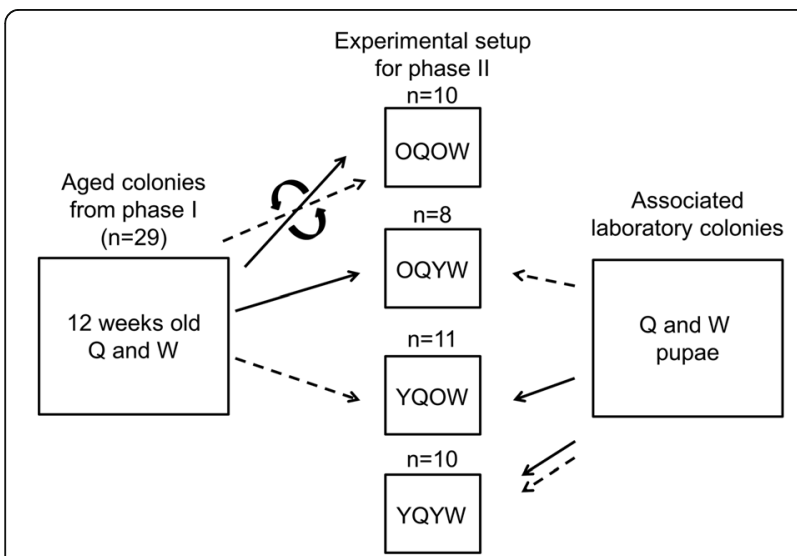

Fig. 1 Experimental setup of Cardiocondyla obscurior colonies. Dotted lines represent workers, continuous lines queens

\section{(b) offspring weight}

To examine offspring biomass, which might indicate its quality, we pooled six freshly eclosed workers (identified by their lighter color) from three colonies per group, killed them by freezing, and weighed them to the nearest 0.1 microgram $(\mu \mathrm{m})$ using a fine scale (Sartorius Micro $\mathrm{SC} 2$ ). To check for changes with the age of the colony, we examined the wet weight of the first six produced workers in phase II (after about eight to ten weeks) and of six workers that have been produced ten weeks later. Measurements were taken twice and the mean was used for analysis.

\section{(c) behavioral observations}

To examine behavioral differences between the different treatments we scanned the behavioral status of workers within 34 experimental colonies (OQOW: $n=9$, OQYW $n=7$, YQOW $n=9$, YQYW: $n=9$ ) for five or six times per day during the first twelve days of phase II. Workers feeding or being located next to a food source were recorded as foragers as C. obscurior workers are too small to measure the quantity of transferred food.

In addition we videotaped the age-dependent motion behavior throughout a worker lifespan. Therefore, we set up three additional colonies with 20 individuals of equal age (see phase I) to avoid any effect of this treatment on the experimental colonies. Two randomly chosen workers of these colonies were separately filmed for $10 \mathrm{~min}$ once per week over a 30 -weeks period. Due to mortality, sample size decreased with time (see Additional file 1: Figure S1). The recorded videos were analyzed by EthoVision XT 10 software (Noldus, Wageningen).

\section{(d) data analysis}

Statistical analyses were conducted using "R" (version 3.1.3 (2015-03-09)) [45]. Generally, colony reproductive output of phase II was compared. Data were normally distributed for the number of eggs and brood items, number of hatched workers and sexuals, weight as well as days until the first offspring hatched (ShapiroWilk normality tests, $p>0.05$ ). Timespan until the first sexuals eclosed and foraging activity were not normally distributed. Offspring number, development and weight were analyzed by the nonparametric PerMANOVA [46] for the effect of queen and worker age and to include the effect of the source colony and the mean number of workers present per colony per scan throughout the duration of phase II. Pairwise comparisons were done by two-tailed Welch Two Sample t-tests in the case of parametric data and Mann-Whitney U-tests in the case of non-parametric data.

Queen and worker survival was compared by KaplanMeier Survival Analysis using the package "survival" [47]. Differences between groups were compared by 
pairwise survival tests with control for a false discovery rate (Benjamini \& Hochberg, function "BH") [48]. As several workers escaped from the experimental nest boxes, only workers whose death could be verified were used for the analysis. The recorded number of deaths therefore differs from the actual number of workers in the experiment. In two colonies, queens escaped from the nest boxes, hence we included these dates as censored data.

\section{Results}

\section{(a) offspring number}

When placed in a new nest without brood, young queens laid their first eggs almost two weeks later than 12 weeks old queens with previous reproductive experience (MannWhitney U-Test: $\mathrm{W}=0.5, p=0.0001 ; n=19$, mean days \pm sd: old queens $2.27 \pm 0.86$; young queens $14.75 \pm 5.61$ ). Consequently, young queens produced fewer eggs than old queens during the first eight weeks after colony set-up (Welch Two Sample t-test: $t=4.8 ; \mathrm{df}=13.4, p=0.0003$, Fig. 2a). Yet, mean egg laying rates over the whole duration of phase II differed not significantly between old and young queens (Welch Two Sample t-test: $t=2.03$, $\mathrm{df}=11.87, p=0.065$ ). Over the whole period II (between colony set-up and queen death, see Material and Methods), queen egg laying rate was significantly influenced by queen age and by the interaction between queen and worker age (PerMANOVA, queen age: $\mathrm{F}=6.4, \mathrm{df}=1$, $p=0.027$; worker age: $\mathrm{F}=2.3, \mathrm{df}=1, p=0.154$; interaction: $\mathrm{F}=6.8, \mathrm{df}=1, p=0.02$; average number of workers present per scan: $\mathrm{F}=0.9, \mathrm{df}=1, p=0.36$; stock colony: $\mathrm{F}=0.37, \mathrm{df}=4, p=0.8$ Fig. $2 \mathrm{~b}$ ): old queens laid more eggs, and queens laid more eggs when cared for by workers of similar age.

The mean number of brood items (eggs, larvae, pupae) produced during phase II did not differ among the four groups (PerMANOVA: $\mathrm{F}=2.6, \mathrm{df}=3, p=0.09$ ) but was significantly affected by the interaction between queen and worker age (PerMANOVA, queen age: $\mathrm{F}=2.4, \mathrm{df}=1$, $p=0.14$; worker age: $\mathrm{F}=1.6, \mathrm{df}=1, p=0.26$; interaction: $\mathrm{F}=6.3, \mathrm{df}=1, p=0.02$; worker number: $\mathrm{F}=1.6$, $\mathrm{df}=1, p=0.23$; stock colony: $\mathrm{F}=0.83 .4 ; \mathrm{df}=4, p=0.5$ Fig. 2c).

\section{(b) developmental time}

The developmental time of the brood depended on worker age and was additionally affected by worker number (PerMANOVA, queen age: $\mathrm{F}=0.5, \mathrm{df}=1$, $p=0.5$; worker age: $\mathrm{F}=5.05, \mathrm{df}=1, p=0.049$; interaction: $\mathrm{F}=0.04, \mathrm{df}=1, p=0.9$; worker number: $\mathrm{F}=6.4$, $\mathrm{df}=1, p=0.028$, stock colony: $\mathrm{F}=0.5, \mathrm{df}=4, p=0.76$, Fig. 3a). Old workers reared the queens' first offspring faster than young workers did (Welch Two Sample ttest: $t=-2.3, \mathrm{df}=16.36, p=0.037)$. Colonies with old queens produced the first sexual offspring earlier than colonies with young queens (Mann-Whitney-U-Test:

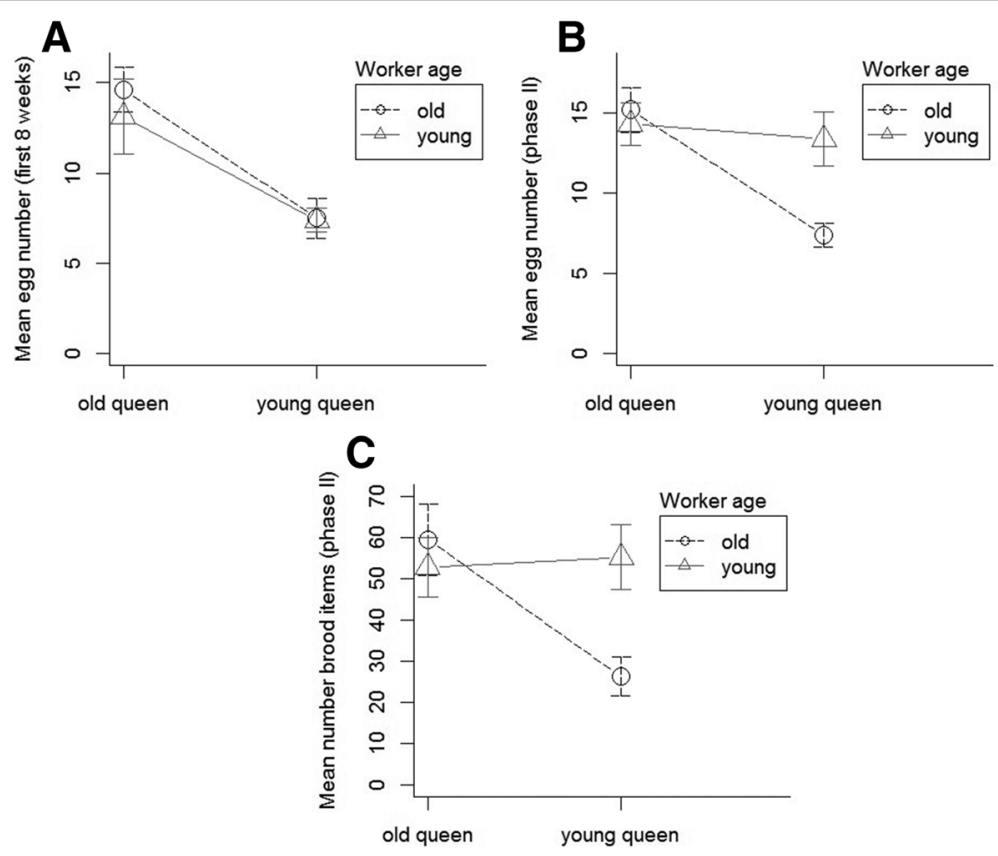

Fig. 2 Brood production in colonies of the ant Cardiocondyla obscurior with different age compositions (mean, 95\% Cl). a Mean number of eggs produced during the first eight weeks after colony establishment and $\mathbf{b}$ ) between colony establishment and the queen death, dependent on queen and worker age (12 weeks old vs. freshly eclosed when the colonies were set up). c Mean number of brood (eggs, larvae, pupae) produced between colony establishment and queen death, dependent on queen and worker age 

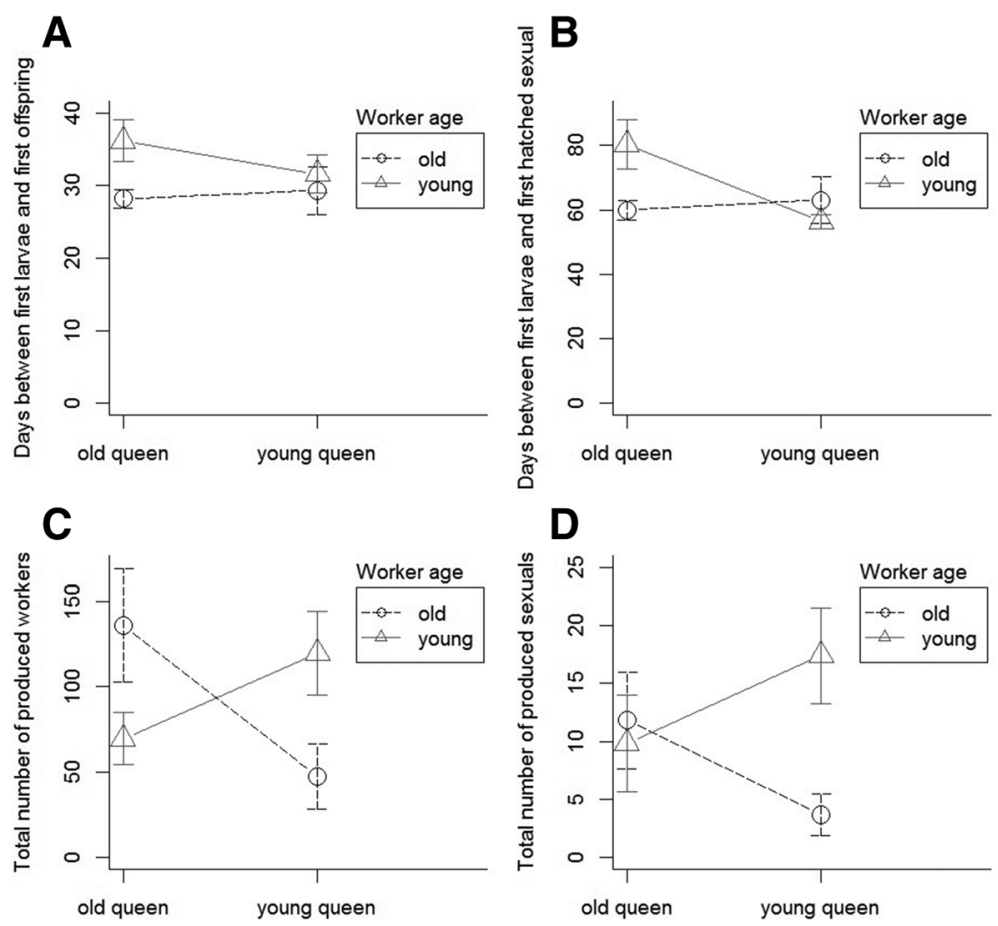

Fig. 3 Timing and success of brood production of Cardiocondyla obscurior colonies with different combinations of old and young queens and workers (mean, 95\% Cl). a Days between first larvae and first hatched worker. b Days between first larvae and first hatched sexual offspring. c Total number of produced workers. $\mathbf{d}$ Total number of produced sexuals

$\mathrm{W}=63, p=0.045)$. Furthermore, the production of the first sexual offspring depended on the queen age and the worker number inside the nest (PerMANOVA, queen age: $\mathrm{F}=6.6, \mathrm{df}=1, p=0.029$; worker age: $\mathrm{F}=2.2, \mathrm{df}=1$, $p=0.17$; interaction: $\mathrm{F}=1.0, \mathrm{df}=1, p=0.34$; worker number: $\mathrm{F}=9.6, \mathrm{df}=1, p=0.015$, stock colony: $\mathrm{F}=1.1$, $\mathrm{df}=4, p=0.4$, Fig. 3b).

Colonies with old queens and young workers or vice versa (OQYW and YQOW) produced fewer worker offspring than colonies in which workers and queens were of similar age (OQOW and YQYW), as worker offspring was affect by the interaction between queen and worker age (PerMANOVA, queen age: $\mathrm{F}=0.09, \mathrm{df}=1, p=0.89$; worker age: $\mathrm{F}=0.26$, $\mathrm{df}=1, p=0.73$; interaction: $\mathrm{F}=5.6, \mathrm{df}=1, p=0.02$, worker number: $\mathrm{F}=0.3, \mathrm{df}=1$, $p=0.69$, stock colony: $\mathrm{F}=1.3, \mathrm{df}=4, p=0.3$, Fig. $3 \mathrm{c}$ ). The number of produced sexual offspring was affected by the interaction between queen and worker age (PerMANOVA, queen age: $\mathrm{F}=0.2, \mathrm{df}=1, p=0.96$; worker age: $\mathrm{F}=0.5, \mathrm{df}=1, p=0.68$; interaction: $\mathrm{F}=3.2, \mathrm{df}=1$, $p=0.04$; worker number: $\mathrm{F}=1.01, \mathrm{df}=1, p=0.4$; stock colony: $\mathrm{F}=1.4, \mathrm{df}=4, p=0.2$, Fig. $3 \mathrm{~d}$ ).

\section{(c) offspring weight}

The wet weight of the first worker offspring depended on queen age and on its interaction with worker age (PerMANOVA, queen age: $\mathrm{F}=15.3, \mathrm{df}=1, p=0.03$; worker age: $\mathrm{F}=1.6, \mathrm{df}=1, p=0.3$; interaction: $\mathrm{F}=13.9$, $\mathrm{df}=1, p=0.028$; worker number: $\mathrm{F}=0.13, \mathrm{df}=1$, $p=0.78$; stock colony: $\mathrm{F}=0.96, \mathrm{df}=4, p=0.5)$. The first workers produced by young queens were lighter than those produced by old queens (Welch Two Sample t-test: $t=2.88, \mathrm{df}=8.18, p=0.02)$. In particular, the offspring produced by young queens and nursed by old workers was very light (Tukey HSD: YQOW vs. OQOW $p=0.01$, other comparisons n. s.). The weight of the later-produced workers was affected by worker age and the worker number (PerMANOVA, queen age: $\mathrm{F}=2.4$, $\mathrm{df}=1, p=0.22$; worker age: $\mathrm{F}=12.6, \mathrm{df}=1, p=0.036$; interaction: $\mathrm{F}=0.85, \mathrm{df}=1, p=0.4$; worker number: $\mathrm{F}=12.9, \mathrm{df}=1, p=0.03$ ), with colonies containing more workers producing heavier offspring.

\section{(d) behavioral observations}

Scan sampling suggested that the workers' foraging activity during the first twelve days of colony founding depended on queen age. Independent of worker age, workers foraged always more in colonies with a young queen in comparison to colonies with old queens, with $30 \%$ and $17 \%$ foraging workers (Mann-Whitney U-Test: $\mathrm{W}=61, p$-value $=0.004)$, respectively (PerMANOVA, queen age: $\mathrm{F}=9.5, \mathrm{df}=1, p=0.0027$; worker age: $\mathrm{F}=2.07, \mathrm{df}=1, p=0.15$; interaction: $\mathrm{F}=0.16, \mathrm{df}=1$, $p=0.82$, stock colony: $\mathrm{F}=0.54, \mathrm{df}=5, p=0.8$ ). 
Video analyses in additional colonies revealed that over the complete period of time, workers travelled less distance (Regression: $\mathrm{R}^{2}=0.26, p<0.001$, Fig. 4) and spent more time immobile with age (Regression: $\left.\mathrm{R}^{2}=0.39, p=0.0002\right)$. Regardless of queen and worker age, workers were observed foraging already during the first day (6 scans) of the experiment (OQOW 2nd scan, OQYW 2nd scan; YQOW 1st scan; YQYW 3rd scan).

\section{(e) queen and worker mortality}

In our experiment, old queens reached slightly longer total life spans than young queens (Log-Rank-Test: $\mathrm{X}^{2}=3.5$, df $\left.=1, p=0.06\right)$. Moreover, queens of the different treatment groups differed in their survival (Log-Rank-Test: $\mathrm{X}^{2}=8.9, \mathrm{df}=3, p=0.03$, Additional file 1: Figure S2). Old queens lived significantly longer with old (median queen lifespan: 35 weeks, Q1: 33, Q3: 35, $\left.\mathrm{X}^{2}=9.6, \mathrm{df}=1, p=0.002\right)$ than with young workers $\left(\mathrm{X}^{2}=9.6, \mathrm{df}=1, p=0.002\right.$; OQYW median queen lifespan: 31 weeks, Q1: 30, Q3: 31) and also longer than young queens living with young workers $\left(\mathrm{X}^{2}=7.5, \mathrm{df}=1\right.$, $p=0.006$; YQYW median queen lifespan: 24 weeks, $\mathrm{Q} 1$ : 23, Q3:27) (for details see Additional file 1: Table S1). It must be noted here that because of the failure of several set-ups (see Methods) sample size was low (OQOW $n=5$; OQYW $n=6$, YQOW $n=3$; YQYW $n=5$ ).

Worker mortality over the entire experimental time (before colony set-up, i.e., phase I, and after colony set-up until queen death, phase II) was determined by the age of workers when the new colony was established. Workers, which had already been 12 weeks old at the beginning of phase II, lived significantly longer than workers, which

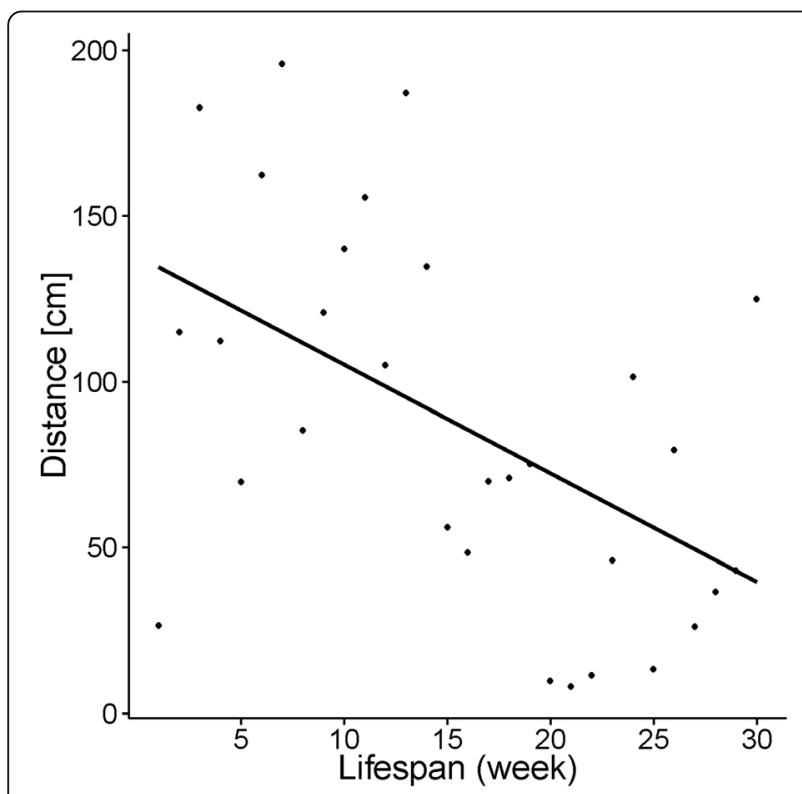

Fig. 4 Distance $[\mathrm{cm}]$ covered by C. obscurior workers of different age during $10 \mathrm{~min}$ had eclosed shortly before colony set-up (Log-Rank-Test: old vs. young workers, $\mathrm{X}^{2}=80.2 \mathrm{df}=1, p<0.0001$ ). During the first four weeks after the beginning of phase II only very few old workers died. The mortality rate of old workers at a chronological age of 12 to 16 weeks at the beginning of phase II was significantly lower than the mortality rate of young workers at a similar chronological age during phase II (Mann-Whitney U-Test: $\mathrm{W}=0$, $p=0.027)$. The proportion of dead workers in colonies with young workers in the first 12 weeks of phase II $(0.30$; period: 12 weeks) was the same as in the 12 weeks of phase I (0.32; period: 12 weeks) (Log-Rank-Test: $x^{2}=0.14$; $\mathrm{df}=1, p>0.5)$. This suggests that the physiological age of old workers was more or less set to zero when transferred into a novel situation of colony founding, i.e., with a new queen and without brood. Additionally, worker mortality was affected by the composition of the colony: young workers live longer when they are together with young queens, while old workers live longer with old queens (Fig. 5) (Log-Rank-Test: $x^{2}=75.3, \mathrm{df}=3, p<0.0001$; for details see Additional file 1: Table S2).

Worker survival and the number of larvae in a colony were correlated (old workers: rho $=0.7, p<0.0001$, young workers: rho $=0.7, p<0.0001$ ), probably reflecting the fact that worker mortality as well as larval number in the colonies increased with time. Similarly, worker mortality and the number of newly eclosed workers were correlated (old workers: rho $=0.5, p<0.01$, young workers: rho $=0.7$, $p<0.0001)$.

\section{Discussion}

We investigated how the chronological age of queens and workers affects reproductive success and the individual speed of aging in the ant Cardiocondyla obscurior. Matching previous observations [49], old queens did not show any signs of reproductive senescence. They initially laid more eggs after colony set-up than young queens,

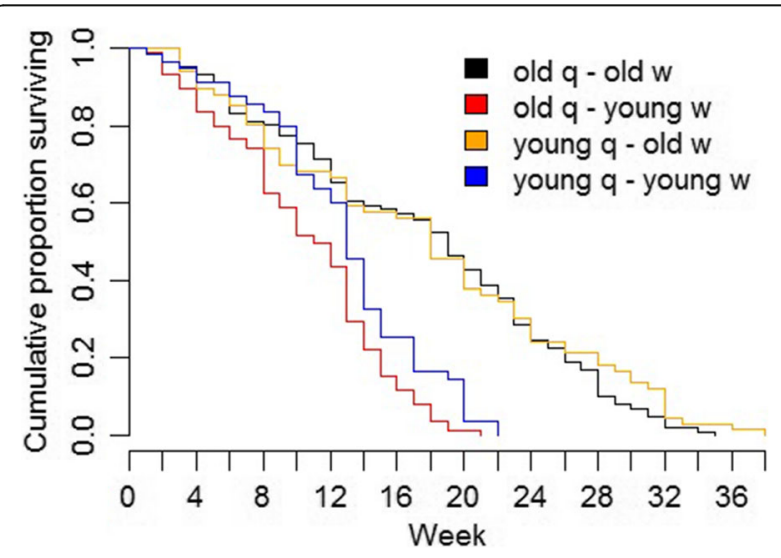

Fig. 5 Survival of workers dependent on queen (q) and worker (w) age during the entire duration of the experiment (phase I + II) 
but the latter caught up with time. Both old and young workers were able to perform all necessary tasks, and colonies produced similar numbers of offspring independent of worker age. This supports the view that task allocation in manipulated colonies of C. obscurior is not strictly age-based but relatively plastic [33], which is consistent with the repertoire expansion model [18].

Nevertheless, colony performance depended on queen and worker age and especially on the interaction between these two factors. Furthermore, the colony age structure had a strong consequence for the residual life spans of individuals: queens lived two to four weeks longer with old than with young workers, and workers, which were 12 weeks old when starting a new colony, outlived workers, which had eclosed shortly before colony founding, by five to eight weeks. Aging in ants therefore appears to depend less on chronological age but on their tasks and the status of the colony, as has previously been demonstrated in honey bee workers [26, 35-37].

Queen age determined the initial growth rate of the newly founded colony, while the age composition of queens and workers gained importance as the colony matured. Colonies with queens and workers of similar age appeared to perform better than colonies in which they were of different age.

\section{Reproductive success}

The egg laying rate of $C$. obscurior queens increases with age $[49,50]$. This explains why in our study old queens laid more eggs than young queens at the beginning of the experiment. Additionally, old queens appeared to produce eggs of a higher "quality," as suggested by higher individual weight of workers produced by old queens. Young ant queens need some time to switch on their reproductive apparatus after mating, and at least queens, which independently found new colonies, invest fewer resources in their first offspring than old, established queens ("nanitic" workers, e.g. [51]). Worker age gains importance when the brood develops as workers are responsible for supplying larvae with food. The brood care experience older workers obtained during phase I might have contributed to the faster development of brood and the increased weight of the first produced worker offspring in colonies with old workers. This supports the hypothesis that workers expand their task repertoire $[18,34]$. Nevertheless, colonies with queens and workers being of the same age (OQOW, YQYW) grew faster and managed to rear more worker offspring. In any case, our data show that old workers are still well capable of efficiently caring for the brood, as previously shown in other social insects $[26,52,53]$; but see [54].
Colonies with old queens and a high worker number produced first sexual offspring most rapidly. However, the total reproductive output was determined by the interaction between queen and worker age, which was reflected by the high number of sexual offspring in young colonies with young queens and young workers.

\section{Worker mobility}

Freshly eclosed workers of $C$. obscurior were capable of adjusting their behavior to the colony needs and to become foragers. In contrast, young workers of Pheidole dentata have been suggested to be behaviorally immature and to be unable to take over new tasks [55]. Young workers of $C$. obscurior left the nest shortly after eclosion and started to forage already during the first few days of our experiment. Their higher mobility and the slower development of larvae in their colonies might reflect their inexperience or developmental immaturity $[55,56]$. Independent of their own age, workers foraged more frequently in colonies with young queens, which probably needed more resources to develop their ovarioles and to increase their egg laying rate than old queens.

\section{Queen and worker lifespan}

The age composition of colonies affected the lifespan of both queens and workers. Old queens reached the highest lifespan when living with old workers. This might be a consequence of the rapid decline of colonies with young workers, which had a much shorter residual life expectancy than old workers. In our experimental colonies without old workers, young workers reached median total lifespans of 11 to 13 weeks, i.e., 2 to 3 weeks less than reported for workers in unmanipulated colonies [43]. In contrast, in colonies consisting of only old workers they outlived "normal" workers by 3 to 4 weeks and the young workers in our experimental colonies by more than 6 weeks.

The OQYW and YQYW treatments of our experiment forced young workers to forage prematurely, which may have accelerated their senescence. Previous studies in honey bees have revealed a negative effect on longevity caused by an earlier onset of foraging [26, 27, 57, 58]. In contrast, in the OQOW and YQOW treatments at least a few old workers had to reverse their tasks and return to brood care. Here, the average mortality rate of old workers stagnated during the first weeks after the colonies were set-up. This clearly documents that the aging trajectory of social insect workers does not depend on their chronological age. Instead, their behavioral status is more important and the transition from foraging to nursing reverses the pattern of aging and senescence (e.g. $[17,52,59-61])$.

While previous studies rarely monitored the exact age of foragers when they reverted to nursing [62], in our 
experiment all workers in OQOW and YQOW colonies were 12 weeks old at the beginning of phase II, i.e., reversal did not only occur among very young foragers. We can exclude an influence of colony size on worker lifespan as reported for the ant Lasius niger and honeybees [58, 63], as worker pupae for the set ups were taken from fully established colonies and worker number was standardized at the beginning of the experiment. Furthermore, at least in honeybees and the ant Platythyrea punctata, the reversal to nursing is associated with increased ovarian development [52,61] and hence physiological changes. Thus, proximately, task and social environment may lead to changes in hormone and vitellogenin titers, which again may affect senescence (e.g. [64, 65]). In contrast, Cardiocondyla workers completely lack ovaries and the reversion to nursing does not alter their "reproductive" status. Still, changes in hormone status are likely to occur but have to be verified in the future $[64,65]$.

Ultimately, the observed plasticity of aging and division of labor in C. obscurior might increase the success of colony founding by budding, i.e., the joint emigration of queens and workers from the natal nest. This process likely changes the age structure of the old and the new colony and requires considerable flexibility in task allocation independent of age.

\section{Conclusions}

In summary, our data show that colonies of C. obscurior, in which all workers are of similar age, develop well, regardless of worker age, but that the interaction between queen age and worker age may have a strong effect on colony productivity. Old queens had a higher reproductive output when starting a new colony together with old workers. While worker age had slight effects on queen longevity, exposing old workers to the conditions of colony founding set their internal clocks back and increased their life spans by $50 \%$. This highlights the enormous plasticity of aging and senescence in social insects and the resilience of division of labor to extreme changes in social organization.

\section{Additional file}

Additional file 1: Figures. S1 \& S2, Tables S1 \& S2. (DOCX 30 kb)

Additional file 2: Raw Data S3. (XLSX 22 kb)

\section{Acknowledgements}

We thank Sarah Steigleder for her help with weighing worker offspring, Magdalena Mair for advice concerning the PerMANOVA, and Tobias Pamminger and an anonymous referee for helpful suggestions on the manuscript.

\section{Funding}

This study was supported by the Deutsche Forschungsgemeinschaft (FOR 2281, Schr 1135/5-1).

\section{Availability of data and materials}

The datasets supporting the results of this article are given in the Additional file 2: (raw data)

\section{Authors' contributions}

$\mathrm{JG}$ performed the experiments and analysed the data; AS designed and coordinated the study; AS, JG, and JH wrote the manuscript and interpreted the data. All authors read and approved the final manuscript.

Ethics approval and consent to participate

Collecting of Brazilian colonies was allowed by Ministério do Meio Ambiente-MMA (Instituto Brasileiro do Meio Ambiente e dos Recursos Naturais Renováveis-IBAMA; Instituto Chico Mendes de Conservação da Biodiversidade-ICMBio) Número: 20324-1. Cardiocondyla obscurior is not protected and an invasive tramp species. All animal treatment guidelines applicable to ants under international and German law have been followed.

Consent for publication

Not applicable.

\section{Competing interests}

The author(s) declare(s) that they have no competing interests.

\section{Publisher's Note}

Springer Nature remains neutral with regard to jurisdictional claims in published maps and institutional affiliations.

Received: 17 February 2017 Accepted: 26 July 2017

Published online: 01 August 2017

\section{References}

1. Aplin LM, Farine DR, Mann RP, Sheldon BC. Individual-level personality influences social foraging and collective behaviour in wild birds. Proc R Soc Lond B. 2014;281:20141016.

2. Brown C, Irving E. Individual personality traits influence group exploration in a feral guppy population. Behav Ecol. 2013:25:95-101.

3. Pruitt JN, Grinsted L, Settepani V. Linking levels of personality: personalities of the 'average' and 'most extreme' group members predict colony-level personality. Anim Behav. 2013;86:391-9.

4. Kohlmeier $P$, Holländer $K$, Meunier J. Survival after pathogen exposure in group-living insects: don't forget the stress of social isolation! J Evol Biol. 2016;29:1867-72.

5. Bergmüller R, Taborsky M. Animal personality due to social niche specialisation. Trends Ecol Evol. 2010;25:504-11.

6. Chapman BB, Ward AJW, Krause J. Schooling and learning: early social environment predicts social learning ability in the guppy, Poecilia reticulata. Anim Behav. 2008:76:923-9.

7. Creel S, Dantzer B, Goymann W, Rubenstein DR. The ecology of stress: effects of the social environment. Funct Ecol. 2013;27:66-80.

8. Chapman BB, Thain H, Coughlin J, Hughes WOH. Behavioural syndromes at multiple scales in Myrmica ants. Anim Behav. 2011:82:391-7.

9. Pinter-Wollman N. Personality in social insects: how does worker personality determine colony personality? Curr Zool. 2012;58:580-8.

10. Giraldo YM, Patel E, Gronenberg W, Traniello JFA. Division of labor and structural plasticity in an extrinsic serotonergic mushroom body neuron in the ant Pheidole dentata. Neurosci Lett. 2013;534:107-11.

11. Schwander T, Rosset H, Chapuisat M. Division of labour and worker size polymorphism in ant colonies: the impact of social and genetic factors. Behav Ecol Sociobiol. 2005;59:215-21.

12. Tripet F, Nonacs P. Foraging for work and age-based polyethism: the roles of age and previous experience on task choice in ants. Ethology. 2004;110:863-77.

13. Wilson EO. Caste and division of labor in leaf-cutter ants (hymenoptera: Formicidae: Atta). Behav Ecol Sociobiol. 1980;7:143-56.

14. Beshers SN, Fewell JH. Model of division of labor in social insects. Annu Rev Entomol. 2001;46:413-40.

15. Giraldo YM, Traniello JF. Worker senescence and the sociobiology of aging in ants. Behav Ecol Sociobiol. 2014;68:1901-19.

16. Mersch DP, Crespi A, Keller L. Tracking individuals shows spatial fidelity is a key regulator of ant social organization. Science. 2013;340:1090-3. 
17. Robinson G. Regulation of division of labor in insect societies. Annu Rev Entomol. 1992;37:637-65.

18. Seid MA, Traniello JF. Age-related repertoire expansion and division of labor in Pheidole dentata (hymenoptera: Formicidae): a new perspective on temporal polyethism and behavioral plasticity in ants. Behav Ecol Sociobiol. 2006;60:631-44

19. Calabi P. Behavioral flexibility in hymenoptera: a re-examination of the concept of caste. In: Trager JC, editor. Advances in myrmecology. Leiden: Brill; 1988. p. 237-58

20. Duarte A, Weissing FJ, Pen I, Keller L. An evolutionary perspective on selforganized division of labor in social insects. Annu Rev Ecol Evol Syst. 2011; 42:91-110.

21. Lenoir A. Feeding behaviour in young societies of the ant Tapinoma erraticum L.: Trophallaxis and polyethism. Insect Soc. 1979;26:19-37.

22. Behrends A, Scheiner R, Baker N, Amdam GV. Cognitive aging is linked to social role in honey bees (Apis mellifera). Exp Gerontol. 2007:42:1146-53.

23. Chang $L H$, Barron $A B$, Cheng K. Effects of the juvenile hormone analogue methoprene on rate of behavioural development, foraging performance and navigation in honey bees (Apis mellifera). J Exp Biol. 2015;218:1715-24.

24. Symonowicz B, Kieruzel M, Szczuka A, Korczynska J, Wnuk A, Mazurkiewicz PJ, et al. Behavioral reversion and dark-light choice behavior in workers of the red wood ant Formica polyctena. J Insect Behav. 2015;28:245-56.

25. Ushitani T, Perry CJ, Cheng K, Barron AB. Accelerated behavioural development changes fine-scale search behaviour and spatial memory in honey bees (Apis mellifera L.). J Exp Biol. 2016;219:412-8.

26. Rueppell O, Bachelier C, Fondrk MK, Page RE. Regulation of life history determines lifespan of worker honey bees (Apis mellifera L.). Exp Gerontol. 2007:42:1020-32.

27. Amdam GV, Rueppell O, Fondrk MK, Page RE, Nelson CM. The nurse's load: early-life exposure to brood-rearing affects behavior and lifespan in honey bees (Apis mellifera). Exp Gerontol. 2009;44:467-71.

28. Rueppell O, Schäffler L, Hölldobler B. Lack of plasticity in the behavior of queens of the ant Leptothorax rugatulus Emery (Formicidae: hymenoptera). J Insect Behav. 2002;15:447-54

29. Arcila AM, Ulloa-Chacon P, Gomez LA. Factors that influence individual fecundity of queens and queen production in crazy ant Paratrechina fulva (hymenoptera: Formicidae). Sociobiol. 2002;39:323-34.

30. Brian M, Hibble J. Studies of caste differentiation in Myrmica Rubra L. caste bias, queen age and influence. Insect Soc. 1964;11:223-38.

31. Petersen-Braun M. Untersuchungen zur sozialen Organisation der Pharaoameise Monomorium pharaonis L.(Hymenoptera, Formicidae) II. Die Kastendeterminierung. Insect Soc. 1977;24:303-18.

32. Rueppell O, Linford R, Gardner P, Coleman J, Fine K. Aging and demographic plasticity in response to experimental age structures in honeybees (Apis mellifera L.). Behav Ecol Sociobiol. 2008;62:1621-31.

33. Oettler J, Nachtigal AL, Schrader L. Expression of the foraging gene is associated with age polyethism, not task preference, in the ant Cardiocondyla obscurior. PLoS One. 2015;10(12):1-7.

34. Giraldo YM, Rusakov A, Diloreto A, Kordek A, Traniello JFA. Age, worksite location, neuromodulators, and task performance in the ant Pheidole dentata. Behav Ecol Sociobiol. 2016:70:1441-55.

35. Amdam GV, Jr REP. Intergenerational transfers may have decoupled physiological and chronological age in a eusocial insect. Ageing Res Rev. 2005;4:398-408.

36. Huang ZY, Robinson GE. Regulation of honey bee division of labor by colony age demography. Behav Ecol Sociobiol. 1996;39:147-58.

37. Robinson GE, Page RE, Strambi C, Strambi A. Colony integration in honey bees: mechanisms of behavioral reversion. Ethology. 1992;90:336-48.

38. Heinze J, Cremer S, Eckl N, Schrempf A. Stealthy invaders: the biology of Cardiocondyla tramp ants. Insect Soc. 2006;53:1-7.

39. Heinze J, Delabie J. Population structure of the male-polymorphic ant Cardiocondyla obscurior. Stud Neotrop Fauna E. 2005:40:187-90.

40. Cremer S, Lautenschläger B, Heinze J. A transitional stage between the ergatoid and winged male morph in the ant Cardiocondyla obscurior. Insect Soc. 2002;49:221-8.

41. Seifert B. The ant genus Cardiocondyla (Insecta: Hymenoptera: Formicidae) a taxonomic revision of the C. elegans, C. bulgarica, C. batesii, C. nuda, C. shuckardi, C. stambuloffii, C. wroughtonii, C. emeryi, and C. minutior species groups. Ann Nat Hist Mus Wien Ser B Bot Zool. 2002;104:203-338.

42. Schrempf A, Heinze J, Cremer S. Sexual cooperation: mating increases longevity in ant queens. Curr Biol. 2005;15:267-70.
43. Oettler J, Schrempf A. Fitness and aging in Cardiocondyla obscurior ant queens. Curr Opin Insect Sci. 2016;16:58-63.

44. Schrader L, Kim JW, Ence D, Zimin A, Klein A, Wyschetzki K, et al. Transposable element islands facilitate adaptation to novel environments in an invasive species. Nature Comm. 2014;5

45. R Development Core Team. R: A language and environment for statistical computing. Vienna, Austria; 2008

46. Oksanen J, Blanchet FG, Friendly M, Kindt R, Legendre P, McGlinn D, et al. vegan: Community Ecology Package; 2017.

47. Therneau TM, Grambsch PM. Modeling survival data: extending the cox model. New York; 2000.

48. Benjamini $Y$, Hochberg $Y$. Controlling the false discovery rate: a practical and powerful approach to multiple testing. J R Stat Soc Series B Stat Methodol. 1995;57:289-300.

49. Heinze J, Schrempf A. Terminal investment: individual reproduction of ant queens increases with age. PLoS ONE. 2012;7(04):e35201.

50. Kramer BH, Schrempf A, Scheuerlein A, Heinze J. Ant colonies do not tradeoff reproduction against maintenance. PLoS One. 2015;10:e0137969.

51. Porter SD, Tschinkel WR. Adaptive value of nanitic workers in newly founded red imported fire ant colonies (hymenoptera: Formicidae). Ann Entomol Soc Am. 1986;79:723-6.

52. Bernadou A, Busch J, Heinze J. Diversity in identity: behavioral flexibility, dominance, and age polyethism in a clonal ant. Behav Ecol Sociobiol. 2015; 69:1365-75.

53. Giraldo YM, Kamhi JF, Fourcassié V, Moreau M, Robson SKA, Rusakov A, et al. Lifespan behavioural and neural resilience in a social insect. Proc R Soc Lond B. 2016;283:20152603.

54. Kwapich CL, Tschinkel WR. Limited flexibility and unusual longevity shape forager allocation in the Florida harvester ant (Pogonomyrmex badius). Behav Ecol Sociobiol. 2016;70:221-35.

55. Muscedere ML, Willey TA, Traniello JF. Age and task efficiency in the ant Pheidole dentata: young minor workers are not specialist nurses. Anim Behav. 2009;77:911-8.

56. Muscedere ML, Traniello JFA, Gronenberg W. Coming of age in an ant colony: cephalic muscle maturation accompanies behavioral development in Pheidole dentata. Naturwissenschaften. 2011;98:783.

57. Dixon L, Kuster R, Rueppell O. Reproduction, social behavior, and aging trajectories in honeybee workers. Age. 2014;36:89-101.

58. Rueppell $\mathrm{O}$, Kaftanouglu $\mathrm{O}$, Page RE. Honey bee Apis mellifera workers live longer in small than in large colonies. Exp Gerontol. 2009;44:447-52.

59. Amdam GV, Aase ALT, Seehuus SC, Fondrk MK, Norberg K, Hartfelder K. Social reversal of immunosenescence in honey bee workers. Exp Gerontol. 2005:40:939-47.

60. Dussutour A, Poissonnier LA, Buhl J, Simpson SJ. Resistance to nutritional stress in ants: when being fat is advantageous. J Exp Biol. 2016;219:824-33.

61. Kuszewska K, Woyciechowski M. Reversion in honeybee, Apis mellifera, workers with different life expectancies. Anim Behav. 2013;85:247-53.

62. Johnson B, Carey JR. Hierarchy and connectedness as determinants of health and longevity in social insects. In: Weinstein M, Lane MA, editors. Sociality, hierarchy, health: comparative biodemography: a collection of papers. Washington D.C: National Academic Press; 2014. p. 269-94.

63. Kramer BH, Schaible R, Scheuerlein A. Worker lifespan is an adaptive trait during colony establishment in the long-lived ant Lasius niger. Exp Gerontol. 2016;85:18-23.

64. Wnuk A, Wiater A, Godzińska E. Effect of past and present behavioural specialization on brain levels of biogenic amines in workers of the red wood ant Formica polyctena. Physiol Entomol. 2011;36:54-61.

65. Amdam GV. Social context, stress, and plasticity of aging. Aging Cell. 2011; 10:18-27. 